\title{
Risk of failure to meet regional and national goals relevant to agricultural development and poverty reduction in South Africa
}

\author{
Simbarashe Ndhleve* and Ajuruchukwu Obi \\ Department of Agricultural Economics and Extension, University of Fort Hare, South Africa.
}

Accepted 7 May, 2013

\begin{abstract}
This study examined whether the Eastern Cape province's district municipalities are on course to achieve local and regional goals of improving agricultural production and reducing poverty. Results show significant strides towards locally set targets and high uncertainty in meeting the regional targets. Out of seven district municipalities, five municipalities are still about $5 \%$ points below the designated $10 \%$ of the annual budget to agriculture, and only three district municipalities scored more that the set $6 \%$ agricultural growth rate. All the seven district municipalities are not in a position to meet the target of $7 \%$ economic growth rate. Econometric simulations using the Hodrick-Prescott filter on data dating from 1995 to 2010 shows that all the seven district municipalities are off-track the set millennium development Goal 1 target with one even retrogressing from that goal. Failure to significantly reduce poverty is largely attributed to the province's failure to boost agricultural production which is an outcome of low and inefficient public expenditure management, inconsistent and misaligned policies. Regional policies should be built on local policies to bring in the desired impact on local development. This study made a strong case for frequent independent evaluation of set goals.
\end{abstract}

Key words: Agricultural productivity, growth, poverty.

\section{INTRODUCTION}

Countries are struggling to improve agriculture and reduce poverty. The millennium development Goal 1, the comprehensive Africa agriculture development programme (CAADP), the Southern Africa development community (SADC) regional indicative strategic development plan (RISDP) and South Africa's provincial development goal (PGDP) highlights the challenges faced by countries in improving the state of agriculture and reducing poverty. Local, regional and global development initiatives have always been recognized as important milestones for development but their overall economic impact has been always mixed (Benin et al.,
2010). In most cases, these initiatives represent a set of time-bound targets.

South Africa is a signatory to all the above mentioned initiatives (African Union, 2003; Somma, 2008; Mwape, 2009; Republic of South Africa, 2010). These initiatives have important implications on improving agricultural production and reducing poverty. Besides these initiatives, South Africa is failing to improve the state of agriculture and reduce poverty significantly (Machethe, 2004; Manona, 2004; Hall and Aliber, 2010; May, 2010; Ndhleve and Obi, 2011). In the Eastern Cape and Limpopo provinces, agricultural production has 
failed to improve in approximately more than 15 years whereas agriculture remains the backbone of their economies (Hall and Aliber, 2010). Such a growth pattern makes the sector's impact on poverty highly dormant and makes farming households susceptible to increased poverty (NEPAD, 2003).

The targeted times for most of these initiatives are either the 2014 or 2015 . Since less than five years are remaining, governments are under increasing pressure to meet set targets. In recent years, South Africa has witnessed country wide strikes and demonstrations on service delivery issues and many development related issues. Failures of similar programmes like the rural development plan (RDP) and the growth, employment and redistribution (GEAR) macro-economic policy, everyone would like to know whether the current policies are on track to meet the intended goals. With the target years on the horizon, it is important to put these new policy dimensions under scrutiny. This study quantifies a set of scenarios for agricultural development and poverty reduction in the study area. It examines whether growth in agricultural expenditure is in accordance with the CAADP goal and SADC RISDP goals, whether progress towards meeting the $6 \%$ agricultural growth target set under the CAADP initiative through accelerated agriculture production is reachable and whether it is possible to meet the provincial PGDP goal and the MDG 1 of halving the 1994 level of poverty by 2014 and 2015, respectively.

\section{Description of initiatives}

Following independence in 1994, the first democratic government of South Africa adopted the rural development programme (RDP), the growth employment and redistribution development programmes in order to address past injustices in the distribution of productive resources. Following failure of these two policies, the government made available the accelerated and shared growth initiative for South Africa (ASGISA), PGDP, land reform policy, the agricultural black economic empowerment (AgriBEE) and adopted various regional initiatives in order to develop the economy. All these latter initiatives are assumed to have been informed by both the failure of previous policies and important development theories, therefore positive results are highly expected. The following description provides information on the PGDP, CAADP, SADC RISDP and the MDG1.

\section{Eastern Cape's provincial growth and development plan (PGDP) 2004 to 2014}

The Eastern Cape province adopted the PGDP in 2004. This programme signifies the province's compliance to the MDGs (Premier of Eastern Cape, 2009). It contains similar goals as that of the MDGs. It aims to maintain an economic growth rate of between 5 and $8 \%$ per annum and target to the 2004 level of poverty by $50 \%$ (Premier of Eastern Cape, 2009). The PGDP was designed to deal with the continuing spread and increase in the incidence of poverty and unemployment, as well as spatial inequality between different regions. This programme recognises the importance of agricultural transformation, infrastructural development, secondary sector, tourism sector, service delivery and the impacts of HIV/AIDS in solving the problem of poverty. In 2009, the Eastern Cape's office of the premier reported that the PGDP is yet to achieve its desired impact of halving poverty by 2014 in the Eastern Cape as almost half of the population of the Eastern Cape has no income and a further $22 \%$ live on less than R800/month.

\section{Regional initiatives}

The problem of poverty and under development in many developing countries has brought about a number of regional initiatives to harness governments and regional partnership roles in reducing poverty and enhancing economic growth. In the following sections regional initiatives aimed at reducing poverty and improving economic growth in South Africa namely; the Africa union new partnership for Africa's development (AU/NePAD)'s CAADP of Southern Africa, the RISDP, and the first millennium development goal (MDG1), are reviewed. South Africa is a signatory to these initiatives (African Union, 2003).

\section{AU/NEPAD's comprehensive Africa agriculture development programme (CAADP)}

In 2001, the new partnership for Africa's development (NEPAD) was formed by the Assembly of Heads of State in Africa to foster growth and development and addresses the challenges of poverty and under development facing the African continent. The comprehensive Africa agriculture development programme (CAADP) under the Africa union NEPAD recognised the importance of agriculture as the cornerstone of sustained growth and poverty reduction. Its main goal is enhance agriculture-led economic growth, eliminate hunger, reduce poverty, eliminate food and nutrition insecurities, and enable the expansion of exports. As targets for a successful implementation, the CAADP employs the millennium development goal (MDG) of reducing poverty and hunger by half by 2015 , through the pursuit of a $6 \%$ average annual growth in the agriculture sector and allocating an average of $10 \%$ of national budgets to the sector (Benin et al., 2010). In partnerships with AU/NEPAD, South Africa is mandated 
to achieve these two goals (African Union, 2003). A report on progress towards the CAADP goals by Somma (2008) concluded that after five years, only a handful of Africa's 53 nations have reached the designated $10 \%$ target. According to NEPAD's 2007 tally, thirteen countries managed to spend from 5 to less than $10 \%$ on agriculture, and 15 more invested less than $5 \%$. The remaining 18 countries, South Africa included, did not report on this. According to Mwape (2009), the number of countries spending more than $10 \%$ increased from $11 \%$ in 2003 to $22 \%$ in 2006 .

\section{SADC's regional indicative strategic development plan (RISDP)}

SADC countries adopted the concept of the poverty reduction strategy papers (PRSPs) in order to formulate strategic plans and earmark financial resources for achieving their poverty reduction goals. Among other goals, the SADC RISDP Target 1 for food security is to achieve a gross domestic product GDP growth rate of at least $7 \%$ per year and halve the proportion of the population that lives below the poverty line between 1990 and 2015 (SADC, 2008).

\section{Millennium development goal (MDG1)}

The millennium declaration adopted by all 191 member states of the United Nations commits these countries to implement eight target-oriented millennium development goals (MDGs) that were formulated to significantly improve human lives by 2015 (UNDP, 2010). The MDG1 targets to halve the proportion of the population living on less than US $\$ 1$ per day between 1990 and 2015. South Africa is committed to achieve the MDGs within the stipulated time, that is, by 2015. South Africa's MDG's Country Report (RSA, 2010) clearly indicated that the country is well on course to meet all the MDGs. Although doubts have been expressed about the feasibility of halving poverty by 2015 (Alemu, 2010).

\section{MATERIALS AND METHODS}

\section{Study area}

Eastern Cape's six district municipalities and one Metropolitan constituted the sample frame. The Eastern Cape Province is highly rural and essentially agrarian in nature and has a wide range of diversity in terms of both geographical and socio-economic characteristics across its municipalities that can add value to the study. It is richly endowed with farming land. Households share some common village resources and using communal land (Hebinck and Lent, 2007). Two-third of the population in the province lives below the poverty line and largely dependents on social grants and surviving through subsistence agriculture (Hall and Aliber, 2007).
For years, the government of Eastern Cape has relentlessly invested in develop the agricultural sector but the sector remains severely underdeveloped.

\section{Data used}

This assessment is based on the data secured from statistics South Africa and Eastern Cape socio-economic consultative council (ECSECC) (2010), the repository of data on all the socio-economic indicators of Eastern Cape. Indicators from 1995 to 2010 were used to tell a credible story of how processes and investments associated with CAADP initiative, SADC PRSP, MDG1 and PGDP are influencing economic growth and poverty in Eastern Cape. Each indicator was evaluated against a purposively selected goal. The selected set goals and indicators which are of interest in this evaluation process are presented in Table 1.

Choosing the base year is an important aspect of trend analysis (Benin et al., 2010). The baseline for all the indicators in this study is 1995, that's the time South Africa began assembling data for the Eastern Cape Province. The baseline year for the CAADP is 2003, the year the Maputo declaration was made (Benin et al., 2010).

\section{Data analysis}

Simple comparative analyses that provide graphical snapshots of municipal current economic indicators and compare it with the set targets of the provincial and key regional set targets were employed. Simulations were made in order to assess whether MDG1 is achievable by 2015 or not. Simulations provide a logical and consistence framework that provides analysts and policymakers with a valuable presentation a sector's performance (Seventer, 2002). Exponential smoothing following the HodrickPrescott Filter was used to make the projections. This method allows the projections of future incidence of poverty using past trends. This method is widely used among macro-economists to obtain a smooth estimate of the long-term trend component of a series. It was used by Cogley and Nason (1995) and Bardsen et al. (1995) in a working paper analysing business cycles. Technically, the Hodrick-Prescott filter (HP) is a two-sided filter that computes the smoothed series of $\tau$ of $y$ by minimizing the variance of $y$ around $\tau$, subject to a penalty that constrains the second difference of $\tau$. That is, the HP filter chooses $\tau$ to minimise:

$\sum_{t=1}^{T}\left(y_{t}-\tau_{t}\right)^{2}+\lambda \sum_{t=2}^{T-1}\left(\left(\tau_{t+1}-\tau_{t}\right)-\left(\tau_{t}-\tau_{t=1}\right)\right)^{2}$

Let $y_{t}$ for $t=1,2, T$ denotes the logarithms of a time series variable. The series $y_{t}$ is made up of a trend component, denoted by $\tau$ and a cyclical component, denoted by $\mathrm{c}$ such that $\mathrm{y}_{\mathrm{t}}=\tau_{\mathrm{t}}+\mathrm{c}_{\mathrm{t}}$. The penalty parameter $\lambda$ controls the smoothness of the series $\sigma$. The larger $\lambda$ is, the smoother the $\sigma$. As $\lambda$ approaches infinity, a linear trend emerges from the $\tau$.

In reporting progress towards MDG1, this study used the same system as the one used by UNDP (2010). See Table 2 for detailed information. The simulated performance of each district municipality with regard to MDG1 follows the above categorizations after comparing it with the target values set. This set of information enables quantification of the deviation from the target and an evaluation to check if the deviation is acceptable. These analyses are narrowed only to assess progress towards the MDG1 only because all the initiatives are assumed to feed into the MDG1 as the mother goal. Understanding progress towards MDG1 will, therefore, also help us understand all the other targets. 
Table 1. Selected Indicators to monitor changes in Agricultural Expenditure, agricultural GDP, total GDP and the incidence of poverty.

\begin{tabular}{ll}
\hline Development initiative, goals and targets & Indicators \\
\hline PGDP & \\
Target 1 : Halve, between 2004 and 2015, the proportion of people & Proportion of the population below US\$ 1 a day \\
whose income is less thanUS $\$ 1$ a day &
\end{tabular}

\section{CAADP initiative}

Target 5: To invest at least $10 \%$ of budget to agriculture

Target 1: To achieve at least 6\% agricultural GDP growth rate

\section{SADC RISDP}

SADC RISDP Target 1: To achieve 7\% GDP growth per year
Share of agriculture expenditure in the budget

Agricultural GDP growth rate

GDP growth rate

MDG1

Target 1: Halve, between 1990 and 2015, the proportion of people Proportion of the population below US\$1 a day whose income is less thanUS\$1 a day

Table 2. Progress towards MDG1.

\begin{tabular}{ll}
\hline Category & Explanation \\
\hline $\begin{array}{l}\text { Early achiever } \\
\text { On track }\end{array}$ & $\begin{array}{l}\text { It has already reached the target. } \\
\text { It is likely to reach the target by } 2015 \text { or any set date. }\end{array}$ \\
Off track/slow & $\begin{array}{l}\text { It has been making progress, but only slowly, so may not reach the } \\
\text { target before } 2015 \text { or any set date. }\end{array}$ \\
Off track/regressing/no progress & $\begin{array}{l}\text { It has made no progress and may even have regressed, moving } \\
\text { further away from the target. }\end{array}$ \\
\hline
\end{tabular}

\section{RESULTS AND DISCUSSION}

The following section presents the results of the evaluations. To contextualize this discussion, a comparative analysis with relevant provincial-level data will be presented.

\section{Eastern Cape's public expenditure evaluation outcome for 2010}

The gaps between the set target expenditure and actual expenditure are shown in Figure 1. The results of the agricultural expenditure tracking survey for Eastern Cape presented in Figure 1 indicates that all the district municipalities have not reached the 10\% target using budget figures for 2010, and the bulk of the district municipalities, five out seven district municipalities are almost within $5 \%$ points of the set threshold.

Some important implications emerge from the above finding. The emphasised role of public investment in agriculture in literature calls for increased spending by the province. It is expected that all the district municipality programs should continue to foster an increase in the size of public spending. Countries that sustained agricultural growth during the Green Revolution were committing $11 \%$ of their budget expenditure to the agricultural sector (Mwape, 2009). This, therefore, implies that there is a need to increase the scale and size of public expenditure across the Eastern Cape Province district municipalities since it is acknowledged to be essential in increasing agricultural productivity.

\section{Agricultural growth rate}

Using the most recent data for 2009 to 2010, Figure 2 presents both the growth rates in provincial GDP and GDP from the agricultural sector for South Africa and the Eastern Cape province and all its district municipalities. Total GDP growth rates are compared with the SADC RISDP Target 1 of reaching a 7\% GDP growth rate. The agricultural GDP is evaluated against the CAADP target of $6 \%$ agricultural growth rate.

The dashed line shows the 7\% GDP growth rate target set under the SADC RISDP target and the bold line 


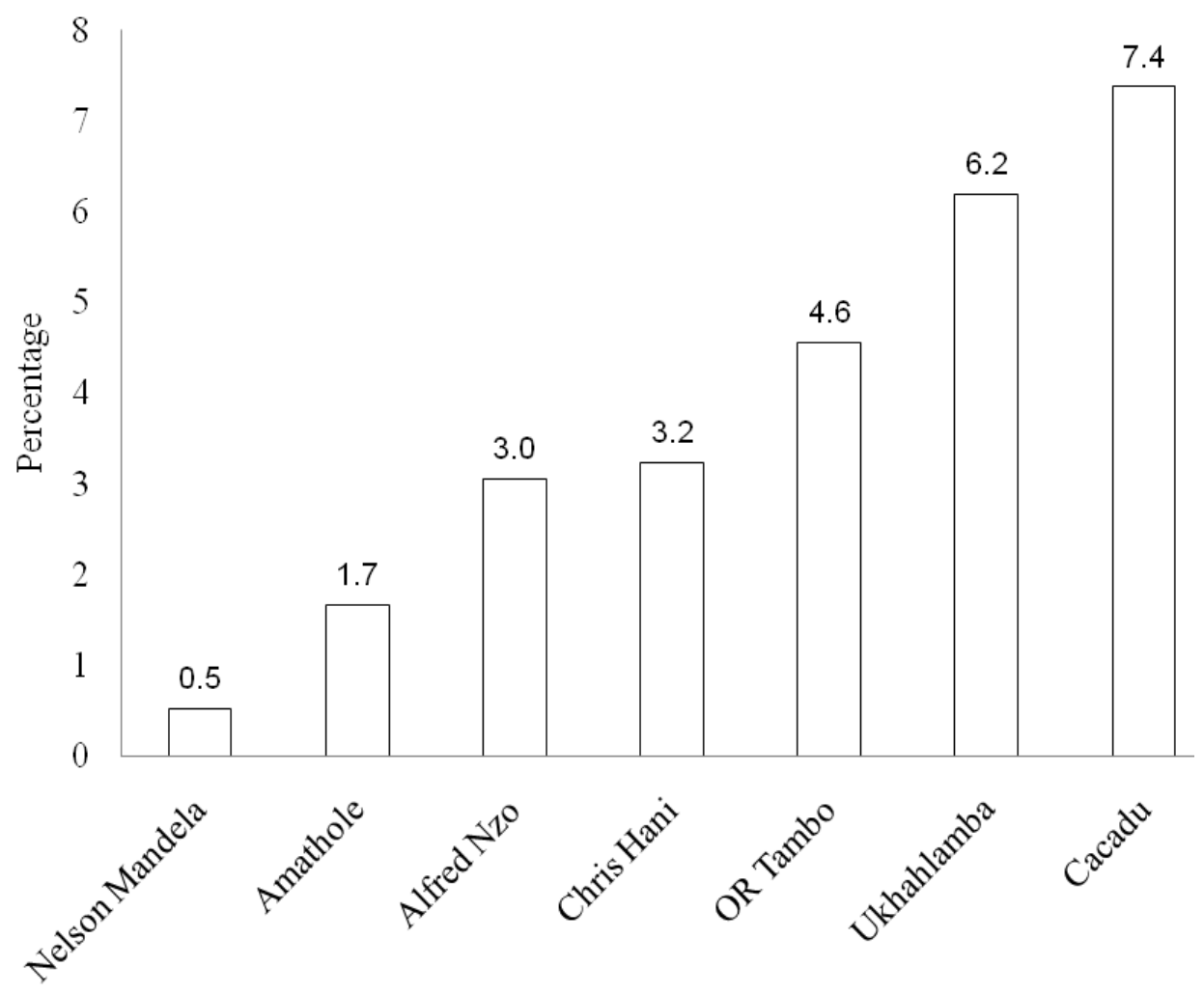

Figure 1. Agricultural Expenditure as a share of Total Expenditure (2009 to 2010), Source: Authors' calculations based on data from Government publications.

shows the 6\% agricultural GDP growth rate set under the CAADP. The presented results shows that the district municipalities are doing relatively well in progressing towards the CAADP target and less well in progressing towards the SADC RISDP Target 1. Using 2009 to 2010 figures, OR Tambo, Alfred Nzo and Amatole district municipalities scored more than the set $6 \%$ growth in the agricultural sector. This is a reflection of significant progress towards the $6 \%$ agricultural growth rate set by the CAADP. When comparing figures for 2009 to 2010 for Cacadu and Chris Hani district municipalities, the chances of reaching the CAADP target are in great doubt. These two districts scored a growth rate of less than $3 \%$.

Relative to the SADC RISDP target, the situation across district municipalities is depressing. When comparing progress towards the SADC RISDP target with the CAADP target discussed above, progress towards this goal is less impressive. Using figures for 2009 to 2010, Figure 2 shows that prospects towards the achievement of the 7\% growth rate in GDP remains gloomy as all the district municipalities scored a growth rate less than the set $7 \%$ growth rate. Four district municipalities are far from reaching both the CAADP target of $6 \%$ growth in agricultural GDP and the SADC RISDP target of $7 \%$ growth in total GDP. It is virtually impossible to meet the MDG1 in the province in the absence of agricultural growth and GDP growth. Meeting MDG1 requires support to the agricultural sector and all the other sectors that make up the total GDP. An effort should be made to duplicate the development activities implemented in the three prospering municipalities that have achieved the set targets or Tambo district municipality should be used as model of growth.

\section{Progress towards MDG1 and SADC RISDP}

Figure 3 presents a snapshot of the margin between the current level of poverty and the targeted value for the incidence of poverty under these two initiatives. The results in Figure 3 show that all the district municipalities have not halved poverty levels as the graphs present the variations between the set target for both the MDG1 and the SADC RISDP and the current level of poverty in 2009 to 2010.

With five years left, the prospects of reducing the level of poverty across the seven district municipalities are bleak with the most doubtful prospect being in respect to five district municipalities namely Amatole, Chris Hani, UKhahlamba, O. R. Tambo and Alfred Nzo. Poverty levels in all these five districts are well above the set SADC RISDP and the MDG1 target, with some even recording more than $60 \%$. 


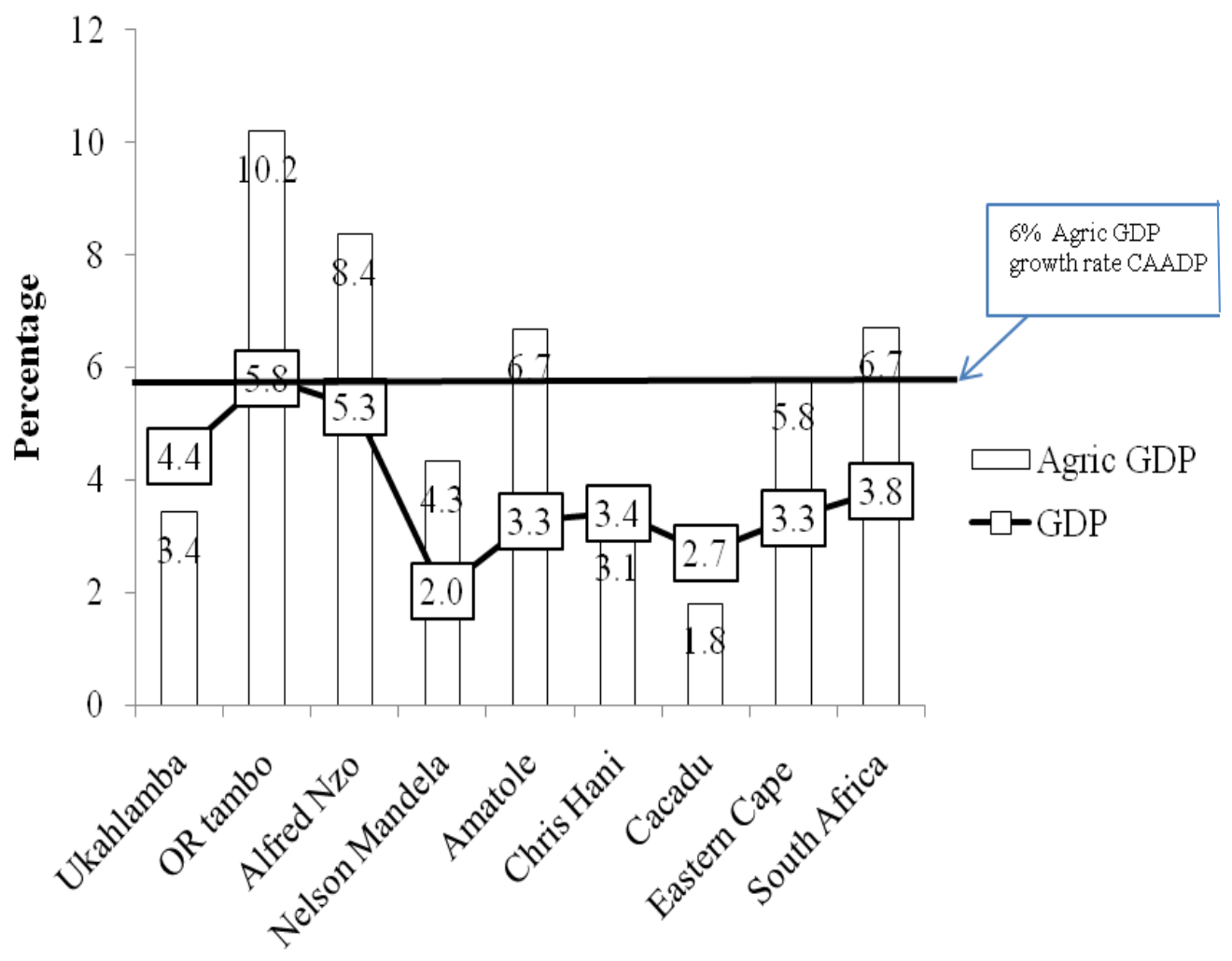

Figure 2. Total GDP and Agricultural GDP Growth Rates; Source: Authors' calculations based on data from ECSECC (2010) database.

$\square$ Current Value (2010) $\quad \sim$-Target Value (2015)
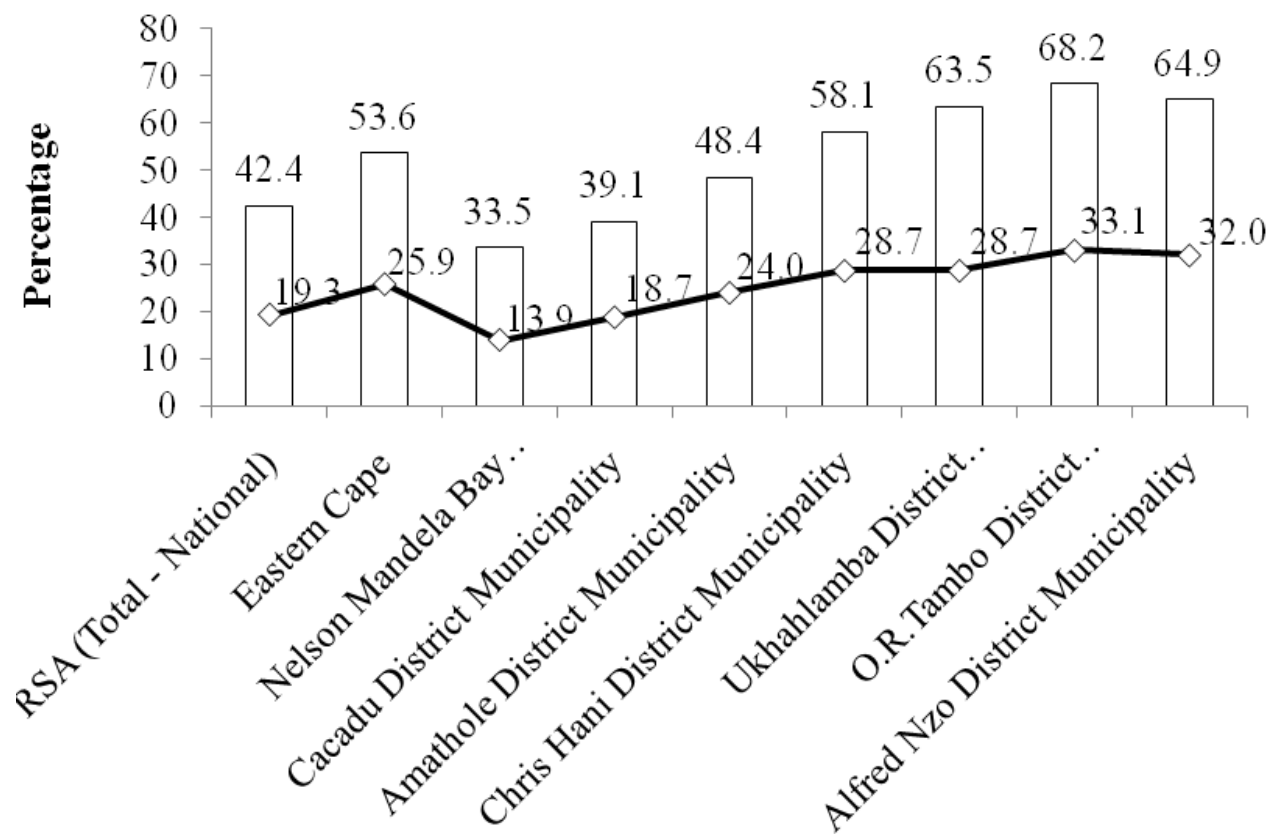

Figure 3. Changes in Poverty and progress towards MDG1 and SADC RISDP; Source: Authors' calculations based on data from ECSECC. 


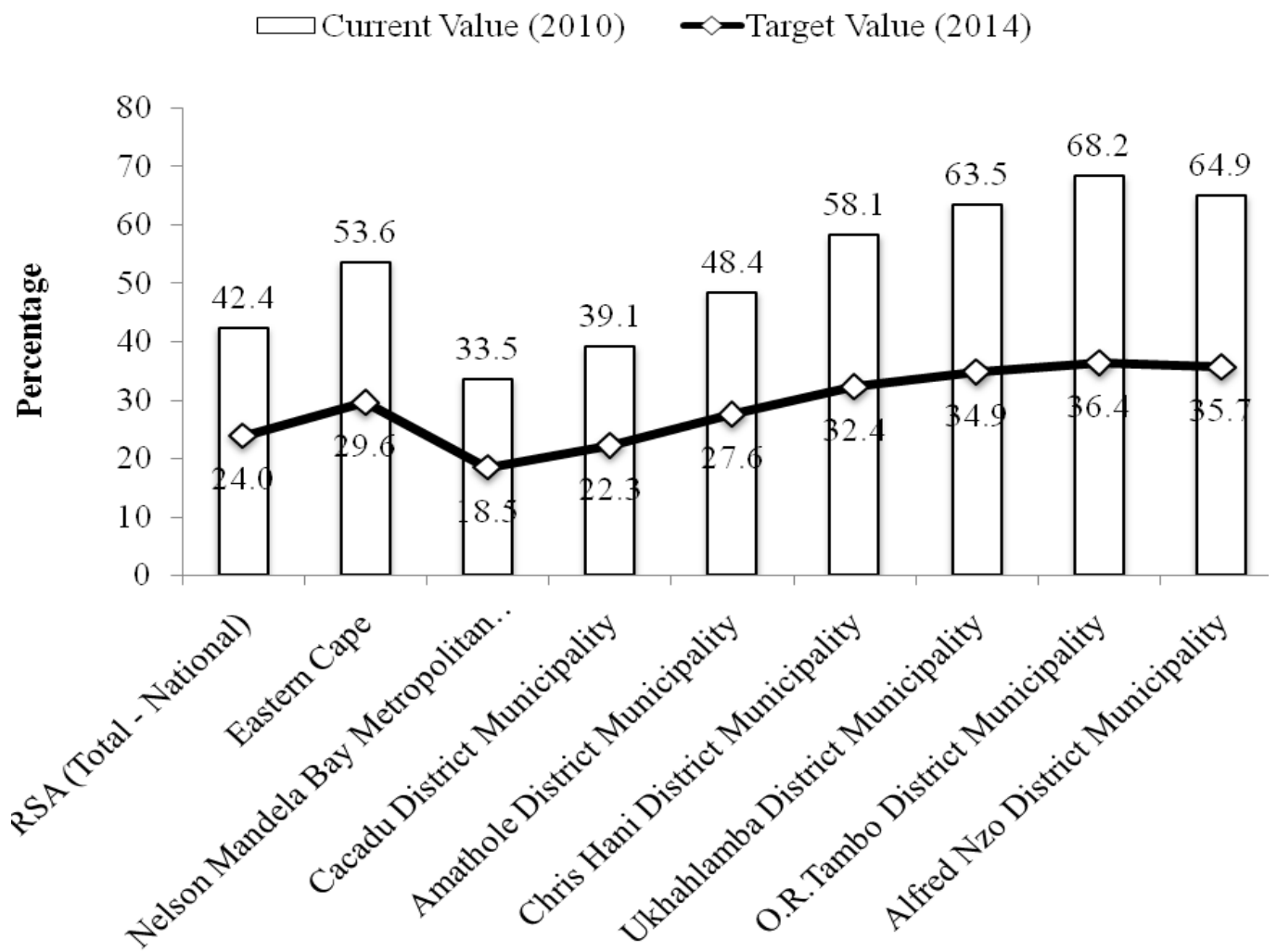

Figure 4. Changes in Poverty and progress towards PGDP, Source: Authors' calculations based on data from ECSECC (2010) database.

\section{Level of progress towards PGDP}

Using 2004 as the base year, Figure 4 compares the seven district municipalities' 2009 to 2010 poverty levels with the target set under the PGDP with respect to poverty. Huge variations still exist between the set target and the figures for 2009 to 2010 . However, considering that the PGDP initiative was only implemented less than six years ago, in 2004, the district municipalities seem to have reduced poverty by noticeable percentage points. With five years left, the prospects of achieving the PGDP target are good across all the districts municipalities since the reductions in poverty shown in Figure 4 are noticeably linked to the initial level of poverty for 2004.

The MDG1 and the PGDP share a similar goal of halving the proportion of the poor although the target incidence of poverty is different due to altered base year. It is therefore deemed important to compare progress towards these targets in the province under study. Figures 3 and 4 suggest that all the district municipalities are pprogressing relatively well towards the PDGP compared to the MDG1. Both figures show a large variation between the target value and the achieved value for 2010. The average margin between the target percentage and the percentage for 2010 is relatively lower under the PGDP than what appears in Figure 3 showing progress towards the MDG1. The PGDP seems to be presenting a slightly impressive picture of progress towards poverty reduction relative to the MDG1. This might imply that the set of planning under the PGDP is better than that of the MDG.

The adoption of both the PDGP and the MDG1 was a landmark decision for the Eastern Cape Province's district municipalities. From the above results, it is obvious that both the 2014 deadline for PGDP and the 2015 deadline for MDG1 were optimistic. The above results show that the prospects of achieving both the PGDP and MDG1 by 2014 and 2015 are highly unlikely as the differences between the current value and the set targets are still high with less than five years left. Even though there is limited progress, the observed changes from the base year provides enough justification for the province to commit resources in line with the two policy frameworks. Further inferential statistics on progress towards the set poverty level that takes into consideration the past trend in annual changes in the incidence of poverty and the forecasted trend over the next five years will be presented in the following section, succeeding discussion of the above results.

Although, it is difficult to isolate the impacts of PDGP and MDGs, the above results show slight variation in progress towards the PGDP and MDG1. The outcome 
that the Eastern Cape province is progressing better towards the PGDP target than the MDG1 target reflects importantly on the variations in the impact of regional policy as compared to local policies. PGDP is a local policy framework designed for the Eastern Cape province and the MDGs are global programmes. It is important to note that a good set of policy frameworks and set targets may not necessarily produce commensurate gains in terms of poverty reduction. In fact, for many countries the effects of regional or global policies have been noticeably smaller than that of local policies. This suggests that the province had a potential for reducing poverty faster using local development policy frameworks rather than regional policies. This situation is not surprising given the variation between the impact of local policy and that of regional policies observed in across Eastern Cape district municipalities. The fact that the PGDP is an initiative specifically meant for the Eastern Cape Province cannot be taken lightly. Progress noted under the PGDP is probably attributed to the suitability and appropriateness of the set of policies drawn for the programme relative to the MDG which is a set of umbrella policies for all countries. It is probable that local policy could have a magnified impact on poverty relative to a regional policy because of stronger involvement of either country or provincial leadership and stakeholders in the implementation of the local programmes unlike global programmes.

Another factor that must also be taken into account is the process by which the policies have been derived, under either the MDG1 or the PGDP. Since the Eastern Cape Province guided the PGDP, the provincial government officials and consultants have been quite influential in facilitating the process, thus the better results. The MDGs have been driven by world leaders without sufficient prior national or grassroots consultations with inhabitants of the Eastern Cape province or other entities for that matter. This is mostly the case with all countries. This might be the probable reason why the PGDP has a higher marginal impact on poverty than the MDG1. New agricultural development programmes should be tailor made to support the current programme in place, not necessarily replacing them. The advent of new growth frameworks needs to accommodate the previous capacities upon which the sector is presently working on. The success of these development arrangements is highly possible when implementing.

The use of provincial policy in conjunction with regional policy or global policy can improve the efficiency of resource use in the Eastern Cape province. Policy making at provincial level can improve efficiency in the use of public resources, especially the allocation of public funds. The theoretical premise of decentralization of policy making for greater efficiency in the provision of public goods and services to meet local demand seems to be materialising in South Africa when comparing progress towards MDGs with that of the PGDP. The subnational governments are always assumed to be efficient in both policy and use of public funds as they are relatively better in aligning either expenditures or polices with local priorities (Momoniat, 1998).

\section{Eastern Cape's district municipalities' progress towards MDG1}

Inferential statistics showing trends in the incidence of poverty up to 2010 and the consequence of continuing with the observed trends in poverty reduction over the next five years are presented in Table 3 where figures for the base year and current status are compared to the estimates for 2015 and 2025 assuming a Business as Usual Scenario ${ }^{1}$.

Using 1995 to 2010 estimates, various district municipalities will not meet the poverty target, by neither 2015 nor 2025. Except for Nelson Mandela Metropolitan, all the district municipalities have been making progress albeit, slowly. In Nelson Mandela Metropolitan poverty is even increasing implying retrogression, moving further away from the set target. The observed retrogression in Nelson Mandela Metropolitan might be the effect of urbanization. In the Eastern Cape province, amongst all the seven district municipalities, none is considered on track to achieve the MDG1. The MDG1 should be effectively be integrated into all the district municipalities development planning process and municipalities should be increasingly used as a vehicle through which governments seek to operationalize their agriculture and poverty reduction strategies.

\section{Conclusion}

Progress towards both local and regionally set targets is not uniform across district municipalities. Progress towards the CAADP target, the SADC RISDP and the PGDP presented mixed results across municipalities. However, all the municipalities are yet to register notable declines in poverty as the most challenging goal is the MDG1. This goal is seemingly unreachable both in 2015 and 2025. This implies that the province would require more robust pro-poor growth well above historical rates. This result calls for immediate action in improving the sectors that contributes to high marginal reductions in poverty in every municipality. In most municipalities, failure to meet the PGDP goal and the MDG1 is largely attributed to the province's failure to boost agricultural production. Therefore, a case is made for articulation of strengthened provincial comprehensive agricultural public expenditure programs that build a consensus for increased levels and efficiency of public expenditure for agriculture development to levels above historical rates.

${ }^{1}$ Baseline scenario that examines the consequences of continuingcurrent trends in the population, economy, technology and human behaviour. 
Table 3. Achievement of poverty targets in Eastern Cape.

\begin{tabular}{|c|c|c|c|c|c|}
\hline District municipality & $\begin{array}{c}\text { Base year } \\
1994 \text { to } 1995\end{array}$ & $\begin{array}{c}\text { Current } \\
\text { status } 2010\end{array}$ & $\begin{array}{c}\text { Estimate } \\
2015 \\
\end{array}$ & $\begin{array}{l}\text { Progress towards } \\
\text { target by } 2015\end{array}$ & $\begin{array}{l}\text { Progress towards } \\
\text { Target by } 2025\end{array}$ \\
\hline Amatole & 50.9 & 45.6 & 47.1 & Off track/slow & Off track/slow \\
\hline Alfred Nzo & 68.2 & 61.2 & 62.9 & Off track/slow & Off track/slow \\
\hline Cacadu & 40.4 & 36.7 & 38.5 & Off track/slow & Off track/slow \\
\hline Chris Hani & 62 & 54 & 56.1 & Off track/slow & Off track/slow \\
\hline Nelson Mandela Metropolitan & 30.8 & 30.9 & 34.2 & $\begin{array}{l}\text { Off track/retrogressing/ } \\
\text { no progress }\end{array}$ & $\begin{array}{l}\text { Off track/retrogressing/ } \\
\text { no progress }\end{array}$ \\
\hline O R Tambo & 69.8 & 64.1 & 66.4 & Off track/slow & Off track/slow \\
\hline UKhahlamba & 62.9 & 60.0 & 63.3 & Off track/slow & Off track/slow \\
\hline
\end{tabular}

Source: Author's simulations based on data from ECSECC (2010) using Hodrick-Prescott Filter (HP), (see Equation 5.6).

Abbreviations: CAADP, Comprehensive Africa agriculture development programme; GDP, Gross Domestic Product; MDG, millennium development goals; SADC RISDP, Southern African development community regional indicative; strategic development plan; PGDP, Provincial growth and development plan; ECSECC, Eastern Cape socio-economic consultative council; NEPAD, new partnership for Africa's development; AgriBEE, agricultural black economic empowerment; ASGISA, accelerated and shared growth initiative for South Africa.

\section{REFERENCES}

African Union (2003). Assembly of the African Union: Maputo Declaration. 10-12 July. Available online: www.africaunion.org/root/au/Documents/Decisions/hog/12HoGAsse mbly2003.pdf.Accessed on the 28th March 2009.

Alemu ZG (2010). Measuring poverty, deprivation, and progress in service delivery: Application to the Eastern Cape Province, South Africa. Seminar presented at National Agricultural Marketing Council, Pretoria August 18, 2010. Development Bank of South Africa.

Bardsen G, Fisher P, Nymoen R (1995). "Business Cycles: Real facts or fallacies? Working Paper presented in the Centennial of Ragnar Frisch, Oslo.

Benin S, Johnson M, Omilola B, Beintema N, Bekele H, Chilonda P, Davis K, Edeme J, Elmekass A, Govereh J, Kakuba T, Karugia J, Makunike R, Massawe S, Mpyisi E, Nwafor M, Olubode-Awosola F, Sanyang S, Taye B, Wanzala M, Yade M, Zewdie Y (2010). Monitoring and Evaluation (M\&E) System for the Comprehensive Africa Agriculture Development Programme (CAADP).ReSAKSS Working Paper No. 6. Washington, D.C.: International Food Policy Research Institute (IFPRI).

Cogley T, Nason J (1995). "Effects of the Hodrick-Prescott Filter on Trend and Difference Stationary Time Series: Implications for Business Cycle Research". J. Econ. Dyn. Control Vol. 19.

ECSECC (2010). Statistical Database. Available online: www.ecsecc.org/statistics-database. Accessed on the 20 October 2011.

Hall R, Aliber M (2010). The Case for Re-Strategising Spending Priorities to Support Small-Scale Farmers in South Africa. Institute for Poverty, Land and Agrarian Studies (PLAAS), Working paper 17. University of the Western Cape.

Hebinck P, Lent PC (2007). Livelihoods and landscapes: The people of Guquka and Koloni and their resources. Leiden, Boston.

Machethe LC (2004). Agriculture and poverty in South Africa: Can agriculture reduce poverty? Department of Agricultural Economics,
Extension and Rural Development and Postgraduate School of Agriculture and Rural Development, University of Pretoria.

Manona WW (2004). Impact of health, water and sanitation services on improving the quality of life of poor communities. Unpublished Doctoral dissertation, Stellenbosch, Stellenbosch University.

May J (2010). Poverty Eradication: The South African Experience. United Nations Conference Centre, Addis Ababa, Ethiopia. Available online:

http://www.un.org/esa/socdev/social/meetings/egm10/documents/Ma y\%20paper.pdf Accessed on the 11th January, 2011.

Momoniat I (1998). Fiscal decentralisation in South Africa: A practitioner's perspective. Available online:http://info.worldbank.org/etools/docs/library/128819/Momoniat $\% 202001 \% 20$ South\%20Africa.pdf. Accessed on the 14 October 2011.

Mwape $F$ (2009). How are countries measuring up to the Maputo declaration? CAADP Policy Brief. June 2009. Available online: http://www.sadc.int/index/browse/page/104. Accessed on 14 April 2011.

Ndhleve S, Obi A (2011). "Determinants of household activity choice, rural income strategies and diversification". Institutional Constraints to Smallholder Development in Southern Africa, Wageningen Academic Publishers, The Netherlands.

NEPAD (2003). Comprehensive Africa Agriculture Development Programme. Process and scope of the Agriculture Programme. Available online: www.nepad.org/system/files/caadp.pdf. Accessed on the 13 March, 2011.

Premier Eastern Cape (2009). Assessment of the Eastern Cape Provincial Growth and Development Plan. Final Report. Bisho, Eastern Cape.

Republic of South Africa (2010). Millennium Development Goals: Country Report 2010. StatSA: Pretoria.

SADC (2008). Regional Indicative Strategic Development Plan. Available online: http://www.sadc.int/index/browse/page/104. Accessed on 14 April 2011.

Seventer EV (2002). Evidence-based Employment Scenarios: Appropriate analytical tools for economy-wide analysis of employment creating policies in South Africa. Trade and Industrial Policy Strategies (TIPS). Human Sciences Research Council.

Somma A (2008). The 10\% that could change Africa. IFPRI Forum: International Food Policy Research Institute, Washington, D.C.

UNDP (2010). Millennium Development Goals country report 2010. Available online: www.statssa.gov.za/news_archive/Docs/MDGR_2010.pdf. Accessed on the 13 May 2011. 